\title{
PAISAJES Y ESPACIOS COMUNES EN EL HÁBITAT POPULAR COLECTIVO El tejido urbano-habitacional de departamentos de pasillo y pasajes en Palermo (Buenos Aires)
}

\author{
Víctor Franco López \\ Universidad de Buenos Aires \\ Director de la tesis doctoral: Fernando Néstor Murillo / Co-Directora: Lorena Vecslir \\ E-Mail: victorfrancolopez@gmail.com
}

\section{RESUMEN}

Frente a la crisis urbana global actual, potenciar las inteligencias colectivas instaladas en los territorios y recuperar el sentido político de la vivienda como hacedora de ciudad podría darnos claves para repensar el habitar contemporáneo. El análisis del hábitat popular se propone como opción para estudiar formas alternativas de eficiencia económica, ambiental y social basadas en el paradigma emergente del procomún y la gestión comunitaria como forma de organización. Para ello, se plantea que los espacios comunes generados a partir del hábitat popular pueden representar los gérmenes de posibles tejidos urbanos más sustentables. Con Buenos Aires como escenario, en el presente texto se exploran inicialmente las tipologías de "departamentos de pasillo" y "pasajes" del barrio de Palermo, con el objetivo de intentar evidenciar el tejido urbano-habitacional resultante de los procesos históricos, poniendo en valor sus potencialidades como arquitecturas con densidad de escala humana, espacialmente más justas y económicamente colaborativas.

Palabras clave: hábitat popular colectivo - espacios comunes - departamentos de pasillo - pasajes

\begin{abstract}
Faced with the current global urban crisis, enhancing the collective intelligences installed in the territories and recovering the political sense of housing as a city maker could give us keys to rethink the contemporary dwelling. The analysis of the popular habitat is proposed as an option to study alternative forms of economic, environmental and social efficiency based on the emergent paradigm of commons and community management as a form of organization. For this, it is argued that the common spaces generated from the popular habitat can represent the germs of possible more sustainable urban fabrics. With Buenos Aires as a scenario, the present text initially explores the typologies of "corridor departments" and "passages" of the neighborhood of Palermo, with the aim of trying to highlight the urban-housing fabric resulting from historical processes, putting value their potentialities as human scale architectures, spatially more fair and economically collaborative.
\end{abstract}

Key words: popular habitat - corridor departments - passages - common spaces 


\section{CRISIS, DERECHOS Y EMERGENCIAS}

Desde hace años, varios autores vienen alertando que la propia estructura del sistema económico-político capitalista en el que vivimos lleva asociado a su existencia la sobreexplotación de los recursos del planeta de manera desequilibrada y la afectación cada vez mayor de la conquista de los territorios (Naredo, 2001) (Davis, 2006 [2007]). Asimismo, otros autores hacen hincapié en que la lucha por el acceso a los recursos naturales y humanos por parte de las sociedades más opulentas del planeta ha dado paso a la militarización de la mundialización que imperó el siglo pasado y que todavía perdura y se recrudece en nuestros días, generando crisis humanitarias globales (Amin, 2009), donde los movimientos migratorios masivos son reflejo de ello.

A esta situación dramática del planeta y sus habitantes a varios niveles, se le añade la preocupación proveniente de la urbanización especulativa, que, como denuncia desde hace tiempo David Harvey (1973 [1977]), viene generando un proceso alarmante de destrucción creativa que ha desposeído a las masas de todo derecho a la ciudad. Así, la devastación territorial, la segregación socio-espacial o la desigualdad son sólo algunos de los efectos del capitalismo a través de la urbanización.

Asumiendo que todo aquel que habita la ciudad es un ciudadano que tiene la potestad de reclamar sus derechos como tal, este trabajo abordará a la ciudad ya no sólo como el escenario físico de las manifestaciones sociales, sino como el objeto mismo de las luchas, como sugiere Harvey (2012 [2013]). Desde esta perspectiva, reivindicar la ciudad existente resulta esencial para defender la justicia espacial a escala planetaria; y donde la hibridación y la transculturalidad -frutos de los procesos migratorios de desposesión que generó la globalización- podrían suponer una gran oportunidad para la reformulación de las narrativas de resistencia y acción colectivas, puesto que consiguen aglutinar a grupos minoritarios diversos y entenderlos como parte integradora del camino a trazar.

Durante los últimos años, la calle y los espacios públicos más representativos de las ciudades se ven invadidos masivamente por nuevas reivindicaciones locales, pero al mismo tiempo de alcance global. La denominada Calle Global (Sassen, 2016), como mutación de la Ciudad Global (Sassen, 1991 [1999]) y deseable agenda política para el planeta, va más allá de la gran ágora como plaza física, puesto que añade su dimensión semántica representando ahora a la ciudad como sujeto colectivo. El espacio público tradicional se convierte en el espacio común, donde los límites entre lo real y lo virtual se difuminan, retroalimentándose la esfera física con la esfera digital. La resignificación cultural de los espacios públicos, como aquellos espacios relacionales donde se hibridan las diferentes dimensiones de lo común, está impulsando repolitizaciones de los mismos como espacios de encuentro, debate y empoderamiento colectivo (Gutiérrez, 2016a).

Dentro de estas efervescencias encontramos a los feminismos, ecofeminismos ${ }^{1}$ o feminismos comunitarios ${ }^{2}$, y a los ecologismos o ecologismos sociales ${ }^{3}$ como focos radicales que trabajan en la esfera de la cultura, aportando críticas filosóficas sobre el patriarcado, la jerarquía, la moral, el antropocentrismo o el racionalismo. Estos debates, como cuestiona Corner (2014), se encuentran con poca frecuencia en los discursos urbano-territoriales. Según él, sólo será a través de una comprensión más sofisticada de la ecología -una que trasciende su condición de una ciencia natural descriptiva y analítica y reconoce su capacidad metafórica como construcción cultural- y a través de una arquitectura paisajística más creativa y significativa que este proceso se podrá realizar. En este sentido, quizás uno de los retos más importantes por delante que tienen los urbanistas no reside sólo en la forma espacial ni en la apariencia estética, sino que se vuelve esencial relacionarlo con los procesos de producción espacio-temporal, hacia ciudades más justas e inclusivas espacial, política, económica y ecológicamente (Corner, 2009).

\footnotetext{
${ }^{1}$ Como explica Alicia H. Puleo, este término surge del encuentro entre feminismo y ecología y "en su variedad de corrientes abre un horizonte prometedor para feministas y ecologistas" (Puleo, 2010: 169).

${ }^{2}$ Este tipo de feminismo coloca en el centro de las reivindicaciones a la defensa de la comunidad como objetivo feminista de las luchas contra el sistema patriarcal opresor. Es bastante extendido en América Latina, especialmente en Bolivia (con la figura destacada de Julieta Paredes) y en México (destacando los aportes de Raquel Gutiérrez Aguilar).

${ }^{3}$ Según James Corner, "de las diversas ecologías radicales, la que parece ser de particular interés para la arquitectura del paisaje es la ecología social", puesto que en ella "la idea de ecología trasciende sus características estrictamente científicas y asume dimensiones sociales, psicológicas, poéticas e imaginativas" (Corner, 2014: 268-269).
} 


\section{LA VIVIENDA POPULAR FRENTE AL PENSAMIENTO ÚNICO Y LA BÚSQUEDA DE UNA ESPECIE LATINOAMERICANA}

Frente a esta crisis urbana global, la revalorización de las arquitecturas populares como una fuente de inspiración y de enseñanza se hace realmente importante y debería introducirse de manera urgente en el aprendizaje formal de las facultades de arquitectura. Se hace referencia aquí a un tipo de hacer arquitectura que se propone en minúscula y plural, que abarca aquellas arquitecturas cotidianas, tradicionales y artesanales, donde gracias a la experiencia y observación históricas se puede dar respuesta a la complejidad intrínseca al hecho de construir en el aquí y el ahora sin dejar de lado la riqueza cultural de un territorio y sociedad determinado.

Con la instauración de la hegemonía económico-política de los países del "norte", y como efecto de la globalización que lo acompaña y expande, se ha estandarizado la arquitectura hasta constituir una especie de modelo a seguir. La instauración del denominado "pensamiento único" en todas las latitudes, que lo que hace "no es plantear soluciones para problemas (o mejor dicho, situaciones) existentes, sino plantear problemas a los que hay que buscarle solución" (Asensio, 2007), se ha conseguido universalizar la doctrina de forma vertical y unidireccional desde la prepotencia de Europa y Estados Unidos como proveedores del saber. Este hecho ha provocado la pérdida de la sabiduría tradicional de la mayoría del planeta, la incorporación de estándares descontextualizados y la dependencia de los países dominantes.

El territorio latinoamericano no quedó afuera de estos caducos y atrofiados paradigmas urbanos internacionales resultantes del proceso de mundialización y "menos aún encontramos esfuerzos de adaptación, apropiación o siquiera ejemplificación en nuestros territorios, relegados a la condición de objetos expectantes de alcanzar las complejidades centrales en una suerte de renovada confianza en el mito del progreso lineal e indefectible." (Fernández Castro, 2007). Así, en contra de la transformación de la ciudad que plantea el modelo económico neoliberal en las ciudades, como son la verticalización y la suburbanización como formas del habitar contemporáneo en América Latina, cabe preguntarse cuáles son las tipologías capaces de responder a la demanda de una ciudad sostenible, que facilite el desarrollo de lazos sociales, que permitan la implantación de una actividad económica más horizontal y equitativa y que, a la vez, definan un marco de vida de calidad.

Frente la incapacidad del urbanismo convencional de dar respuestas en este sentido, se hacen necesarios nuevos abordajes, instrumentos conceptuales renovados y posturas metodológicas capaces de hacer frente a las nuevas y complejas realidades en constitución (Fernández Castro, 2007). Para ello, se propone la revalorización de las arquitecturas tradicionales y de las inteligencias colectivas ya instaladas en los territorios. A modo de síntesis genérica al respecto, se utilizará el adjetivo "popular" para denominar a este tipo de arquitecturas, puesto que responde, tal como explica Priscilla Connolly, a un constructo latinoamericano que interesa poner en valor y que encierra una complejidad muy propia de la región (Connolly, 2012). Y siguiendo a la misma autora, cabe destacar que "a pesar de que los aportes teóricos latinoamericanos relativos al fenómenos del hábitat popular han sido transcendentales, [...] han quedado un tanto "marginalizados" por los debates al nivel internacional en los últimos tiempos" (Connolly, 2012: 31), cosa que hace más valioso todavía aportes en este sentido que evidencien, valoricen y difundan teorías propias de la región latinoamericana partiendo desde sus propios hábitats populares.

Con la idea de poner en valor y potenciar las inteligencias colectivas ya producidas, es preciso compartir y difundir los ejemplos de tejido urbano cuyas ideas están basadas en la cooperación, en la dependencia y en la solidaridad, puesto que "[...] los barrios populares no son consecuencia de procesos inmobiliarios o de las instituciones, sino de la acción social y la economía de medios. Este hecho acaba configurando un hábitat con valores rescatables para el urbanismo contemporáneo, como el papel de la vivienda como célula de ciudad, la conservación de la escala humana en el espacio urbano, la mezcla de escalas y usos o la definición de la calle como espacio social" (Sáez; García; Roch, 2010). Así pues, la reivindicación de las arquitecturas tradicionales o populares se debe también como reacción al mencionado modelo hegemónico y universalizador instaurado en la enseñanza de la arquitectura formal, que posterga este saber popular a la mera curiosidad, a lo pintoresco, eludiéndola como ciencia, banalizando sus experiencias y relacionándolas con la pobreza, la escasez y el "subdesarrollo". Estar formados sólo para dar respuestas a un reducido porcentaje de la población que posee los recursos suficientes para hacer frente a un modelo de construcción íntimamente insostenible pone en cuestión la formación del arquitecto y sus prácticas, además de dejar de lado la realidad imperante, comprometiendo al territorio y sus habitantes. 


\section{LOS ASENTAMIENTOS HUMANOS COMO PROCESO}

Focalizar la mirada en la ciudad existente con el objetivo de encontrar claves propias capaces de evolucionar en el tiempo es algo que el ser humano siempre hizo a la hora de transformar sus propios hábitats. Recuperar el papel de la vivienda en la ciudad puede proporcionar nuevos enfoques en la reflexión acerca de un urbanismo más sustentable, puesto que la vivienda popular, como ejemplo de producción social del hábitat, "nos permite evaluar la relación entre las formas de habitar y la sociedad contemporánea, así como estudiar nuevas formas de eficiencia económica, ambiental y social" (Sáez; García; Roch, 2010).

En este sentido, por un lado, el concepto de sustentabilidad urbana que interesa para seguir adelante con el análisis es el denominado de sostenibilidad fuerte por José Manuel Naredo (1996). Así, la sostenibilidad fuerte presupone la equidad entre los miembros de la especie y, en consecuencia, no sólo asegura la viabilidad ecológica y física, sino que también sienta las bases, al menos las necesarias, para una convivencia pacífica y justa con nuestros semejantes. Por otro lado, otro de los conceptos que nos sirven de guía es el de terra fluxus (Corner, 2009), que da cuenta de los procesos cambiantes inherentes a lo urbano. Este abordaje plantea que la ciudad es un ámbito vivo de procesos e intercambios a lo largo del tiempo, que deben analizarse en su conjunto, permitiendo nuevas fuerzas y relaciones que puedan ser capaces de proponer nuevas actividades y modelos de ocupación.

Sin duda, lo que se viene imponiendo es la idea de transformación radical de nuestras insostenibles ciudades modernas y nuestras formas de vivirlas. Parecería que una de las claves de los enfoques territoriales acerca de la construcción de una ciudad sustentable sería la del reciclaje de las mismas ciudades, sin necesidad de construir otras nuevas o, por lo menos, el análisis y reinterpretación del tejido urbano existente en ellas. Pero, más allá de una interpretación puramente formal, en estas proyecciones de nuevas posibilidades para futuros urbanismos, se hace imprescindible entender tanto los principios de organización de las partes y sus relaciones entre ellas (Allen, 2009) como el funcionamientos de las cosas en el espacio y en el tiempo (Corner, 2009).

Así, las reflexiones de Alan Berger (2006) sobre el paisaje urbano como un sistema abierto, donde se entienden a las ciudades no como objetos estáticos, sino más bien como espacios de continuos flujos de energía y transformaciones, abordan a los paisajes, edificios y otras partes duras urbanas ya no como estructuras permanentes, sino precisamente como manifestaciones transicionales. El concepto de condición de campo de Stan Allen también apunta en este sentido, implicando una arquitectura que, más allá de entenderse como una configuración formal, "admite el cambio, el accidente y la improvisación; no es una arquitectura investida de permanencia, estabilidad y certeza, sino una arquitectura que deja espacio a la incertidumbre de lo real" (Allen, 2009: 168).

Para ello, se propone poner el foco en las prácticas creativas de la ecología y la arquitectura del paisaje, como sugiere James Corner, puesto que permitirían "formas alternativas de relación e hibridación entre la gente, el lugar, el material y la Tierra" (Corner, 2014: 279). En base a los principios evolutivos, estas estrategias podrían servir como agentes potenciales de procesos activos y habilitadores de redes emergentes.

\section{COMUNIDADES, REDES COOPERATIVAS Y ECONOMÍAS COLABORATIVAS}

Acorde con la gran complejidad que representan las ciudades, un urbanismo emergente más flexible parece que viene ofreciendo alternativas a los rígidos mecanismos de planificación centralista, donde los temas de organización, interacción dinámica, ecología y técnica pasarían a ser centrales (Corner, 2009).

Durante los últimos años, con la instauración del derecho a la ciudad en los debates y acciones colectivas, se experimenta una relación completamente nueva con lo político. Para ello, la creación de una cultura democrática local, pero sobre todo la movilización y el empoderamiento ciudadano, son necesarios para dicho cambio. El barrio o los círculos más próximos de convivencia parecerían ser los espacios más apropiados para la participación ciudadana y la construcción del sentimiento de pertenencia que empieza a gestar la idea de ciudadanía. Este modelo de ciudad resultante de estos procesos de empoderamiento ciudadano estaría garantizando un derecho que como pobladores urbanos estamos construyendo y donde el hábitat se coloca en el centro del debate. En este sentido, como dice el arquitecto peruano Sharif $S$. Kahatt (2013): "si la arquitectura aspira a recobrar un rol importante en el desarrollo de las ciudades y el paisaje construido, tiene que desarrollar la capacidad de operar en las redes económicas y políticas de la sociedad actual".

Para transformar el cambio social y político que perseguimos para nuestras ciudades es necesario enfrentarse a la hegemonía ideológica del neoliberalismo con una nueva imaginación política que la 
cuestione. Se hace urgente "transformar el terreno de lo político, rechazar la reducción de lo económico a un asunto técnico, reivindicar que lo económico es absolutamente político y que en lo político hay siempre alternativas y esperanzas" (Massey, 2012: 12). La idea es poder interpretar el estado procesual de la construcción de ciudad mediante modos alternativos de evolución siempre dimensionando la existencia del "otro" en el espacio. El respeto y la tolerancia parecen ser los retos que plantea esta dimensión espacial con sentido político y económico que debe primar en nuestras ciudades como forma de convivencia.

Para ello, por un lado, una economía basada en valores éticos que puedan hacer frente al egoísmo financiero debe ser la clave en busca de justicia espacial, a través de la cooperación y la solidaridad de las comunidades. Y, por otro lado, entender la imbricación entre el entorno cultural, social, político y económico al mundo "natural" nos podría llevar al desarrollo de "una ecología espacio-temporal que trata con la totalidad de fuerzas y agentes que actúan en el ámbito urbano y que las considera redes permanentes de interrelaciones" (Corner, 2009: 141).

Estas comunidades o redes, que representan a un grupo de personas que comparten recursos comunes ${ }^{4}$ de tipo tangible, intangible, privados, comunes, públicos, abiertos o cerrados, se caracterizan por "hacer más con menos". De la combinación de recursos y de la capacidad para reinventarlos y combinarlos entre sí va a depender la estructura de la red, así como sus posibilidad de crecer y evolucionar en el tiempo. Así, ciertos desafíos en la creación y gestión de un sistema colaborativo de tipo comunal residen en identificar estos recursos, gestionar correctamente tanto su creación y combinación como su uso y cuidado colectivo (Tamayo, 2016).

Para la conformación y el correcto funcionamiento de estas comunidades cabe destacar la importancia de los "bienes relacionales", cuyo universo cede el espacio a lo colaborativo. Estos bienes intangibles como la confianza, la reciprocidad o la amistad, "son co-consumidos y co-producidos al mismo tiempo por los sujetos involucrados en ellos" (Gutiérrez, 2016b) y están profundamente relacionados a los espacios compartidos. Este modelo de "ciudad relacional" estaría tejido mediante capas de afectos y lazos intersubjetivos, cosa que podría permitir formas de seguridad y control basadas en el encuentro, la relación de vecindad y el diálogo, con la idea de sentar las bases de un "urbanismo que anticipa el cambio, la flexibilidad de soluciones y la negociación" (Corner, 2009: 144). Además, como sugiere Stan Allen (2009), la aceptación de lo real en todo su desorden e incertidumbre podría implicar a los arquitectos desarrollar herramientas y proyectos capaces de considerar las restricciones como una oportunidad, con el objetivo de registrar la complejidad e improvisar en el lugar y en tiempo real.

Este nuevo ecosistema de bienes, relaciones y reciprocidades interdependientes tiene al "compartir" como su ADN y a la vivienda colectiva como su representación simbólica como el espacio de escala de mayor proximidad. La acción de compartir se presenta con potencial para generar nuevas oportunidades económicas capaces de hacerle frente al modelo capitalista imperante recuperando conceptos como confianza o vecindad, bajo nuevos paradigmas como la "economía compartida", la "economía por el bien común"” o el "procomún colaborativo" que vienen transformando las relaciones urbanas.

\footnotetext{
${ }^{4}$ Siguiendo la definición que sugieren desde la plataforma Inteligencias Colectivas, "por los comunes o "el procomún" o bien comunal se entiende aquellos bienes, factores productivos o recursos, procesos o cosas (ya sean materiales o de carácter intangible) cuyo beneficio, posesión o derechos de explotación pertenecen a un grupo o a una comunidad determinada. El grupo en cuestión puede ser extenso, por ejemplo, todos los individuos, o los habitantes de algún país, región, ciudad o pueblo, etc. o restringido, como por ejemplo, una familia o algunos miembros de alguna familia, o grupo de personas establecido para un propósito específico (por ejemplo, una cooperativa o sociedad anónima)". Disponible en: http://www.inteligenciascolectivas.org/ic-az-concept-glosario-terminos-y-textos-dereferencia (consultado el 19.12.16).

${ }^{5}$ El concepto de ciudad relacional que se sigue es el propuesto por la jurista María Naredo (Fernández-Savater, 2013).

${ }^{6}$ Según explican desde Destiempo urbano en el blog de Ciudad Viva, "las economías compartidas, heredadas de antiguas maneras de gestión y remezcladas con las tecnologías de hoy en día, suponen un cambio económico, social y cultural que las políticas locales deben fomentar y potenciar en sus agendas urbanas. Requieren una gran creencia en los bienes comunes (commons), como el espacio público, la educación o la sanidad así como las infraestructuras que dan servicio a la sociedad y deben conseguir, por ello, su espacio en el diseño de las políticas urbanas. Estas iniciativas están consolidándose como una alternativa real, flexible y variable más allá de un antídoto al materialismo y el sobreconsumo de un período de crisis. Muestran la capacidad de ofrecer beneficios sociales y medioambientales, a partir del uso eficiente de los recursos existentes y además el estudio de métricas de este tipo de proyectos demuestra que están generando un beneficio económico de fácil reinversión en la comunidad local", disponible en: https://www.diagonalperiodico.net/saberes/31116-habitar-ciudades-democraticas.html (consultado el 05.05.16).

${ }^{7}$ Concepto acuñado y postulado por el economista austríaco Christian Felber. Más información en la entrevista realizada por Javier Ramajo, disponible en: http://www.eldiario.es/andalucia/Christian-Ferbel 0 558544326.html (consultado el 08.10.16).

${ }^{8}$ Según Jeremy Rifkin, "en la escena mundial está apareciendo un sistema económico nuevo: el procomún colaborativo. Es el primer paradigma económico que ha arraigado desde la llegada del capitalismo y el socialismo a principios del siglo XIX. El procomún colaborativo está transformando nuestra manera de organizar la vida económica y ofrece la posibilidad de reducir las diferencias en ingresos, de democratizar la economía mundial y de crear una sociedad más sostenible desde el punto de vista ecológico" (Rifkin 2014: 11).
} 
Frente a los grandes cambios sociales que venimos experimentando, las reiteradas crisis económicas, financieras y políticas, es necesario transformar las políticas públicas en general y las locales en particular. En este sentido, "podemos afirmar que el bienestar hoy va pasando de ser una reivindicación global para convertirse cada vez más en una demanda personal y comunitaria, articulada alrededor de la vida cotidiana y en los espacios de proximidad" (Subirats; Montaner, 2012), donde la vivienda colectiva y, en especial, el hábitat popular y sus espacios comunes podrían tener un papel fundamental a la hora de repensar el habitar contemporáneo y sus relaciones políticas y económicas.

\section{LOS ESPACIOS COMUNES Y LA COLECTIVIZACIÓN DE LA VIDA URBANA}

La primera conexión con lo público, más allá de lo íntimo, como primera escala de relaciones sociales, es aquella que se da en las viviendas colectivas, convirtiendo a sus espacios comunes como los espacios donde se ejerce la micropolítica, hacedora de ciudad y ciudadanía. Estos espacios como bienes relacionales se producen a través de las interacciones entre los miembros de la comunidad que los use, donde "el espacio es un producto social. Tanto el espacio, digamos, material, como el espacio implícito en nuestros discursos e imaginaciones. $\mathrm{Y}$, si es un producto social, entonces ha de ser también una responsabilidad política. Si es algo que producimos entonces importa cómo lo producimos" (Massey, 2012: 9).

Si entendemos entonces que el espacio se construye a través de relaciones sociales, podemos reconocer la construcción relacional de nuestras identidades personales. Se vuelve imprescindible el encuentro con otros sujetos, puesto que somos, esencialmente, seres sociales en permanente interacción. Como plantea Ignaci de Solà-Morales (2009), el ser urbano, más allá de poder estar desolado por la velocidad con la que el mundo se transforma a nuestro alrededor, está necesitado de convivir con los otros, con el otro. Estos espacios de intimidad representan la dimensión de lo múltiple de la vida cotidiana, al mismo tiempo que influyen en nuestros imaginarios y nuestras actitudes políticas. Por este motivo, el estudio de estos "espacios comunes" parece significativo desde el punto de vista de la escala de proximidad, donde se gesta lo personal y lo comunitario.

En este sentido, cabe destacar que durante las últimas décadas, pero sobre todo de forma más acelerada en los últimos años, la incidencia cada vez mayor de los postulados de Jan Gehl (2014) y su equipo sobre la escala humana poniendo el foco de las decisiones en las personas y no desde una mesa técnica ajena a la realidad o la apuesta por ciudades más amables que fomenten la cohesión social, la protección comunitaria y los cuidados (Gutiérrez Valdivia, 2016) van potenciando la mirada hacia tipologías habitacionales y espacios urbanos capaces de dar respuesta a una relación más estrecha entre espacio físico y vida social; es decir, entre tejido urbano-habitacional y estructura organizacional.

Lo comunitario, dentro del paradigma de "lo común", tiene mucho que ver con esta relación de la que se habla, donde el estudio de los espacios comunes parecerían podernos dar ciertas claves del camino a seguir. Estos espacios comunes, como espacios intermedios o espacios "entre", serían aquellos capaces de poner en relación la escala de lo íntimo con la de lo comunitario y lo urbano, entre el mundo interior y la vida exterior, permitiendo diferentes gradientes de transición. Estos pueden ser de carácter exclusivamente privado hasta los más públicos, pasando por posibilidades intermedias de semipúblicos o semiprivados. Además, pueden permitir diferentes usos comunitarios, áreas de reunión, de esparcimiento, etc. fomentando el encuentro, la puesta en común y las decisiones colectivas; en definitiva, potenciando la micropolítica, como ese eslabón primero de involucración político-social, mostrando la superación de la voluntad individual frente al consenso en las divergencias. Así, como nos sugiere James Corner (2009), estos espacios representan los recipientes de la memoria y del deseo colectivos, además de la imaginación social y geográfica que invita a nuestras relaciones y escenarios de posibilidades. Esta primera instancia más íntima y de escala reducida es, sin duda, un caldo de cultivo para la politización de la sociedad hacia la construcción de las denominadas "ciudades comunes".

Sin duda, analizar estos espacios comunes como superficies entendidas como infraestructura urbana podría sembrar "la semilla de la posibilidad futura, preparando el terreno tanto para la incertidumbre como para la esperanza; esta preparación de la superficie para una futura asignación difiere del interés puramente formal en la simple construcción de superficie; se trata de algo mucho más estratégico, que prima en los medios sobre los fines y la lógica de funcionamiento sobre el diseño de composición" (Corner, 2009: 143).

\footnotetext{
${ }^{9}$ Según Christian Laval y Pierre Dardot, "el término "común" designa, no el resurgimiento de una idea comunista eterna, sino la emergencia de una forma nueva de oponerse al capitalismo, incluso de considerar su superación. Se trata igualmente de un modo de volver la espalda definitivamente al comunismo estatal" (Laval; Dardot, 2014 [2015: 21]).
} 
En definitiva, estos espacios comunes pueden servir como estructuradores de un tejido urbano-habitacional de escala más humana, posibilitando "hacer añadidos a la estructura sin una transformación morfológica sustancial" (Allen 2009: 153) y, al mismo tiempo, favoreciendo "sentimientos de pertenencia e identidad de la población, aportan una mayor calidad y cualidad espacial, favorecen la relación entre la arquitectura y la ciudad, proponen formas de agregación de la vivienda más eficientes y ofrecen una forma gradual de ocupación del espacio urbano. Son espacios flexibles que acaban asumiendo funciones no planificadas y que aseguran mejores condiciones de reproducción social" (Sáez; García; Roch, 2010: 109). Así pues, el estudio de tipologías donde estos espacios intermedios ya vienen funcionando como base del sistema relacional entre unidades habitacionales podría ser de gran ayuda a la hora de repensar el hábitat contemporáneo, revelándose como una interesante herramienta operativa a incorporar para el proyecto de barrio y de ciudad.

\section{TIPOLOGÍA DE HÁBITAT POPULAR COLECTIVO EN PALERMO: LOS "DEPARTAMENTOS DE PASILLO" Y LOS "PASAJES"}

Con la ciudad de Buenos Aires como escenario, y con el objetivo de encontrar ciertas características propias, ya instaladas en los territorios, capaces de funcionar como gérmenes de posibles utopías urbanohabitacionales con la idea de proponer mecanismos de densificación para la ciudad existente, poniéndola en valor, en el presente texto se comienzan a analizar ciertas tipologías de hábitat popular colectivo y sus espacios comunes. En este sentido, el barrio de Palermo sirve como paradigma de los procesos de transformación que sufre la ciudad en la actualidad, siendo foco de atracción debido a su tejido homogéneo, horizontal y con cualidades espaciales y culturales rescatables para el urbanismo contemporáneo, en contradicción con la cada vez más acuciante especulación del suelo en la zona, debido justamente al polo de atracción de clases más pudientes que representan los actuales procesos de gentrificación y turistificación. A este análisis inicial de los departamentos de pasillo y pasajes en el barrio de Palermo se le pretenden sumar los conventillos de San Telmo y las viviendas autoconstruidas de Barrio 31, que darán forma a la investigación en curso de la tesis doctoral.

La evolución del tejido urbano de Buenos Aires, según nos explica Jorge Ramos (1998), consistió a finales del siglo XIX y principios del XX, con la llegada masiva de inmigrantes procedentes de diversos puntos del continente europeo, en un proceso de densificación "en horizontal" del tejido edificado. Esta acción, producida por la subdivisión de las parcelas y el surgimiento de versiones reducidas de los tipos edificatorios tradicionales de la casa de patios, fue generando un tejido cada vez más denso y compacto.

Siguiendo a Fernando Diez (2011), durante esa época de gran ebullición y con un fuerte impulso marcado por la necesidad, se fueron ensayando cambios tipológicos acuciados por la presión demográfica, cosa que provocó la reducción progresiva de la parcela típica. Esta reducción del ancho de las parcelas tuvo su límite mínimo en $8,66 \mathrm{~m}$. (o 10 varas), medida resultante de la subdivisión de las varas de las manzanas originales y tiene a la "casa chorizo" ${ }^{10}$ como tipología habitacional representativa (ver figs. 1 y 2).

\footnotetext{
${ }^{10}$ La tipología de la "casa chorizo" se constituía por un patio lateral de $4 \mathrm{~m}$. junto a una habitación contigua también de $4 \mathrm{~m}$. Las medidas de estos ambientes fueron resultante de la división mínima de las manzanas tradicionales a la que se llegó en la época y junto con el espesor de los muros se estipuló en $8,66 \mathrm{~m}$. coincidiendo con la medida de 10 varas, medida según la cual estaba constituida la manzana porteña.
} 


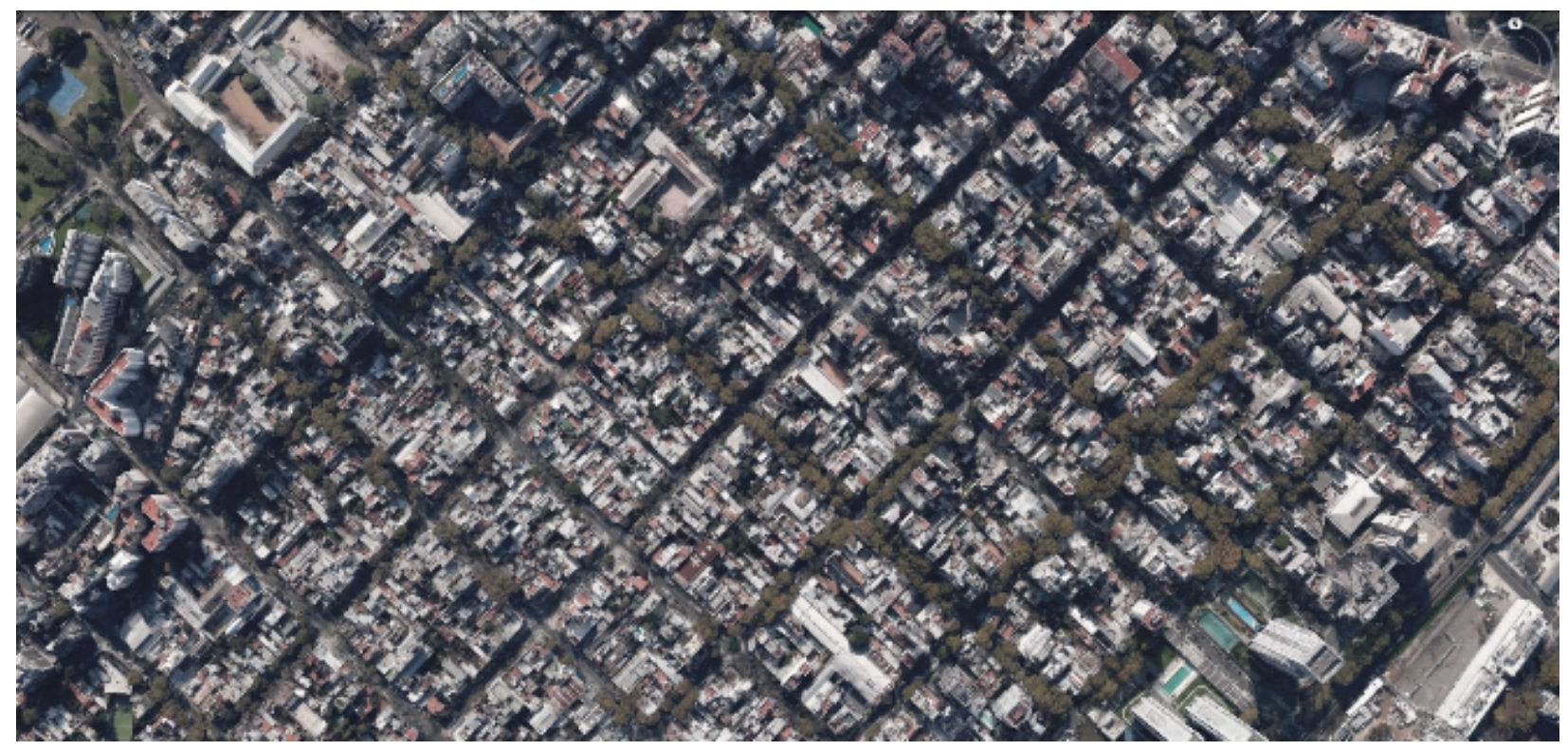

Fig. 1: Imagen aérea con foco en Palermo Hollywood, evidenciando la compacidad y densidad del tejido existente. Se reconocen algunos pasajes. Fuente: GoogleMaps.

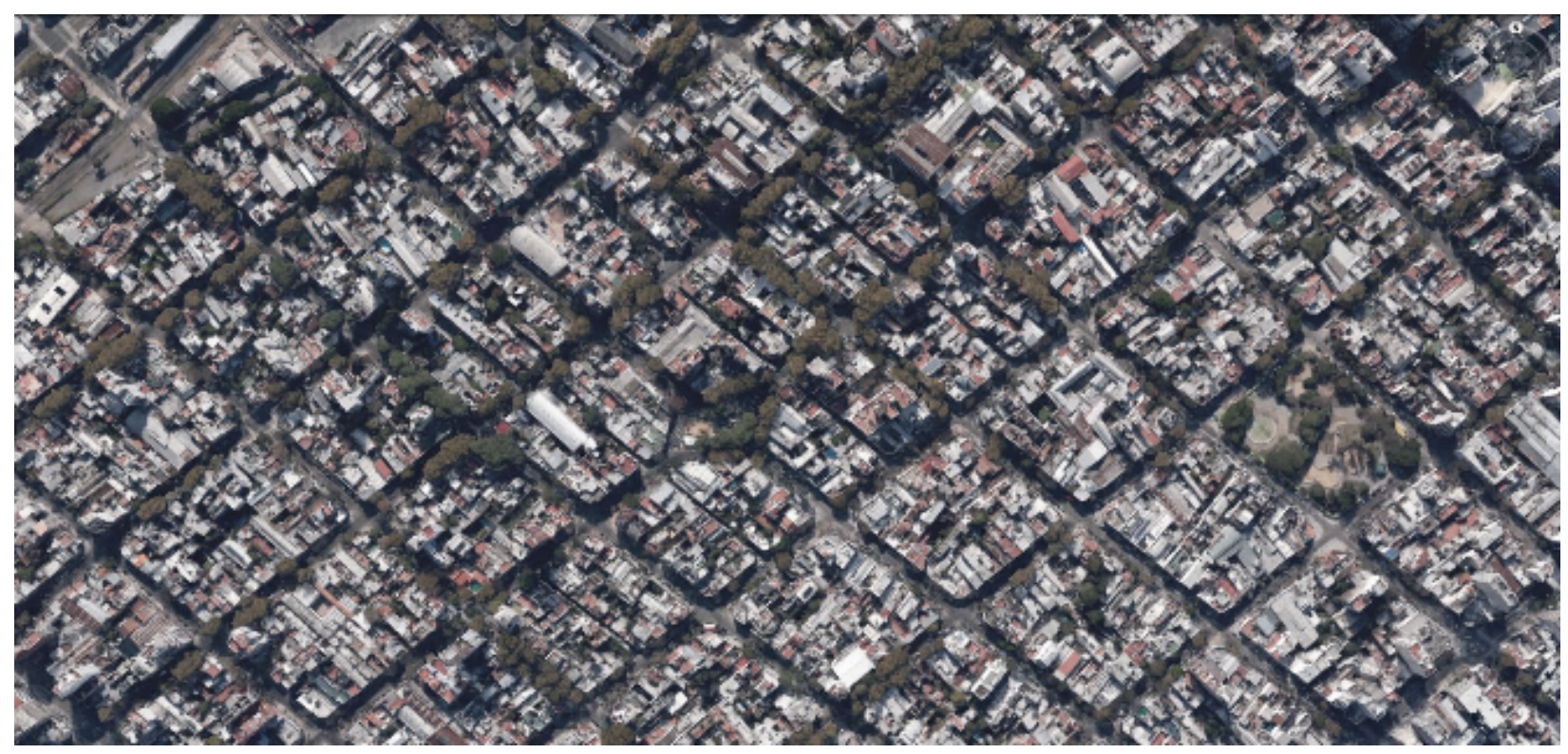

Fig. 2: Imagen aérea con foco en Palermo Soho, evidenciando la compacidad y densidad del tejido existente. Se percibe la abundante cantidad de pasajes en la zona. Fuente: GoogleMaps.

\subsection{Departamentos de pasillo}

A partir del descrito proceso de densificación en horizontal y como derivación de la denominada "casa chorizo" como medida de ancho de lote y tipología habitacional, surgen los llamados "departamentos de pasillo", hoy también denominados como "departamentos tipo casa" o más coloquialmente simplemente como "PH". Esta tipología habitacional, fruto de la especulación urbana, representó un mecanismo de densificación notable a principios de siglo XX y se masificó en la Buenos Aires de la época. Palermo fue uno de los barrios donde más predominó esta tipología y donde todavía se encuentran muchos de sus ejemplos, con o sin modificaciones a las estructuras originales. 


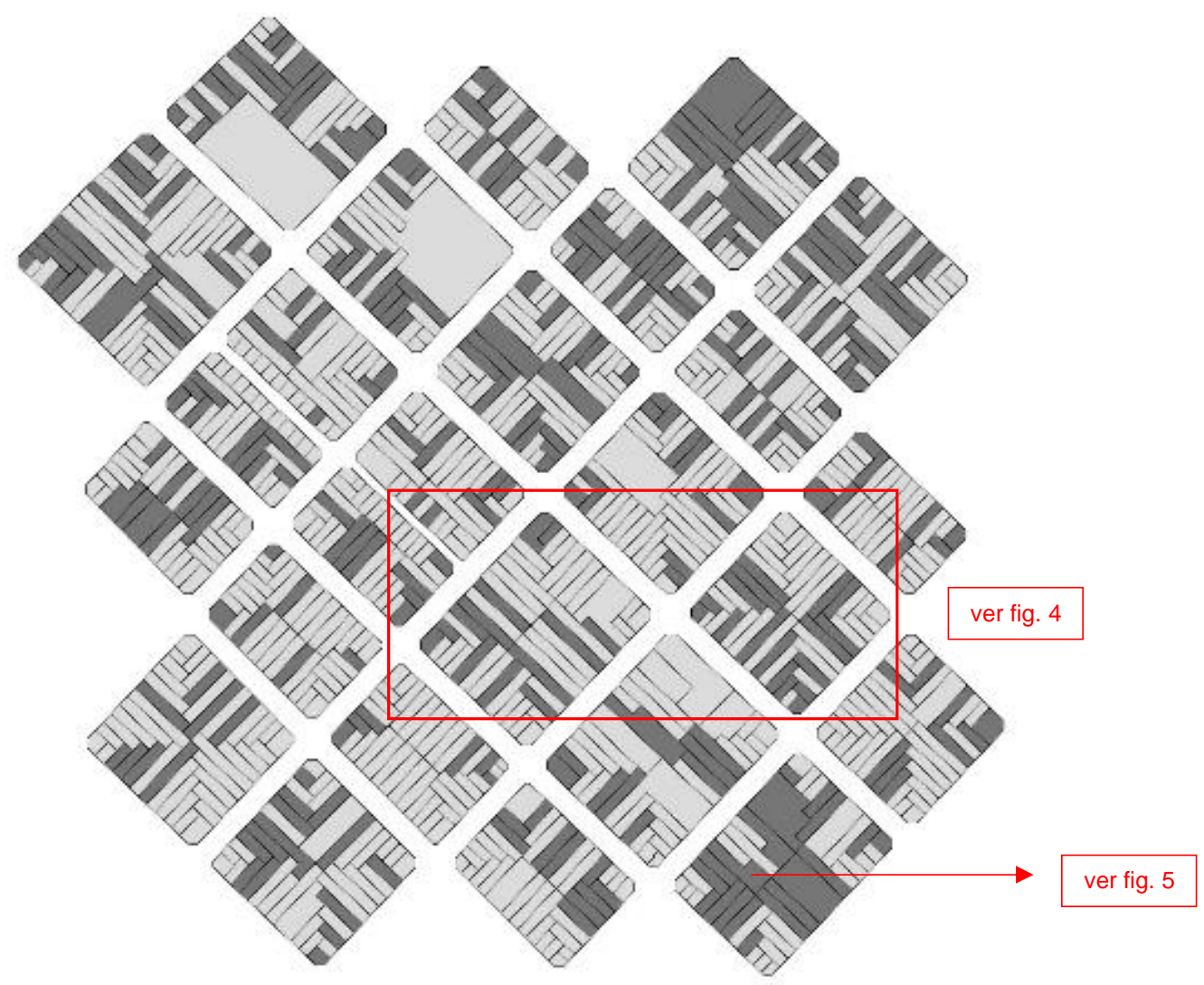

Fig. 3: Mapa del tipo de viviendas en Palermo Hollywood. Los lotes pintados de gris oscuro representan la vivienda colectiva; los de color gris claro, la vivienda individual. Se evidencian los departamentos de pasillo y los pasajes identitarios del barrio. Elaboración propia a partir de la base de datos del mapa interactivo del GCBA.

Estos conjuntos habitacionales modificaron la estructura original de la "casa chorizo", de carácter individual, a viviendas colectivas, cuyas unidades habitacionales se relacionaban mediante un pasillo que funcionaba de estructurador del tejido hacia el interior de la manzana de forma horizontal. Esto permitía el aprovechamiento de la profundidad de los lotes muy angostos y profundos, conformando tejidos de muy alta ocupación del suelo (ver fig. 4). Los pasillos podían ser de tipo lateral o central. En el primero de los casos, la casa chorizo se situaba en la cabeza de la serie de unidades y tenía frente a la calle, dejando simplemente una puerta lateral de acceso al pasillo que permitía la distribución en profundidad a través del lote, dando paso a cada una de las unidades situadas en hilera. En el segundo caso, el pasillo conforma el eje de simetría del conjunto de forma espejada a los conjuntos de pasillo lateral. Además, el pasillo podía estar totalmente descubierto o cubierto en partes o en su totalidad y podía estar sólo en planta baja o en varios niveles como distribuidor internos de las unidades repartidas por el lote. 


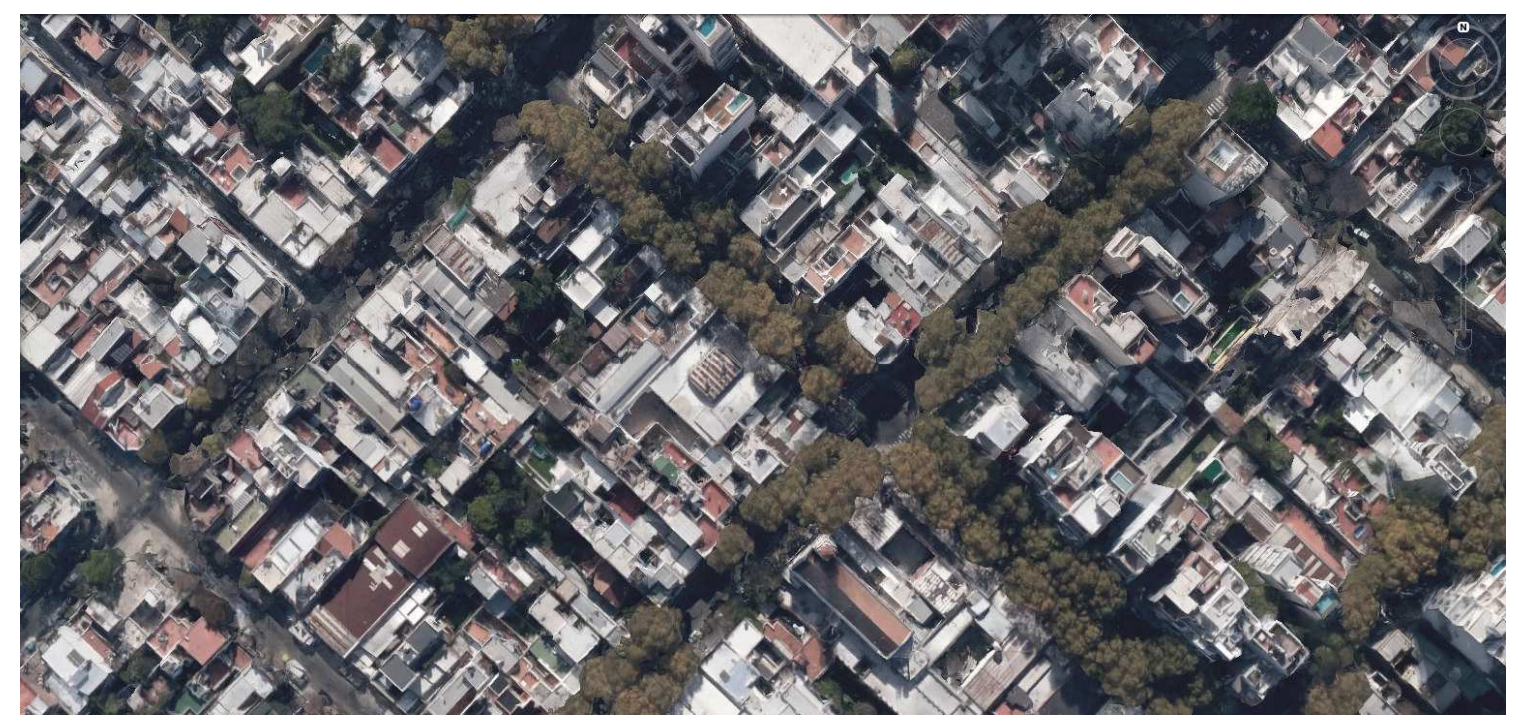

Fig. 4: Zoom del tejido de Palermo Hollywood. Se indica el recorte en la fig. 3. Fuente: GoogleMaps.

Por otro lado, cabe destacar que el proceso de densificación en horizontal también se construyó en altura, resultando ejemplos de un nivel, pero de dos o hasta incluso tres, generando tejidos muy densos y llegando a niveles de hacinamiento y falta de habitabilidad un tanto comprometidos, aunque cuyos límites están poco estudiados en profundidad (ver fig. 5).

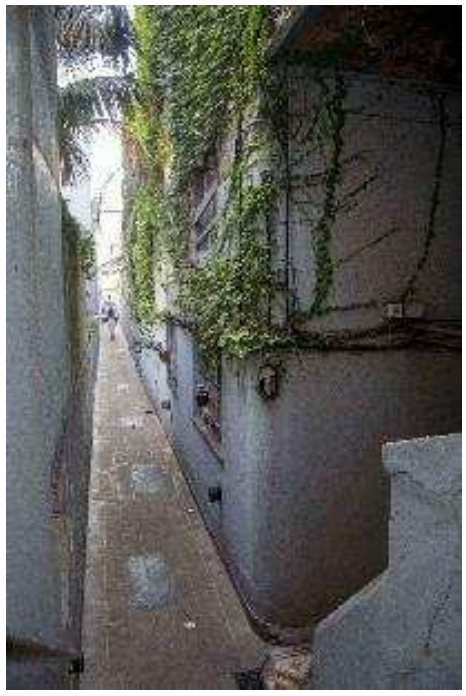

a

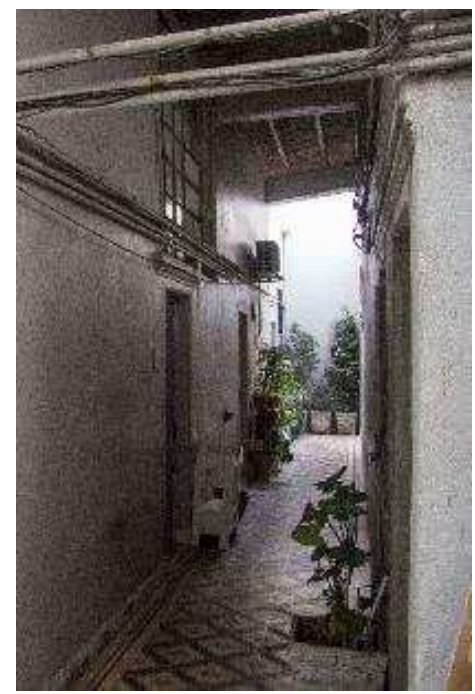

b

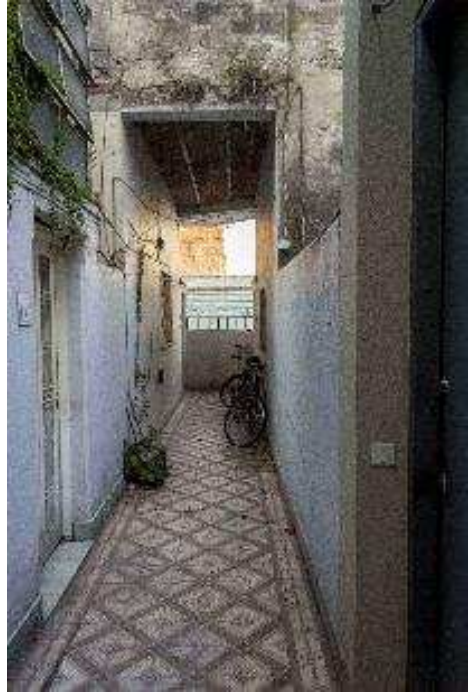

C

Fig. 5: Imágenes de los espacios comunes de un conjunto habitacional tipo "de pasillo". Se señala la ubicación en la fig. 3. Foto a: Vista pasillo colectivo para 9 unidades habitacionales. Foto b: Vista pasillo 5 unidades PB. Foto c: Vista pasillo 4 unidades P1. Fotografías: Silvia Millanes.

Los departamentos de pasillo, a pesar de suponer mejoras en las instalaciones sanitarias y la aparición de espacios propios (y no sólo colectivos) para cocinar, es verdad que en ellos se perdió el carácter más comunal de espacio de convivencia que tenía el patio del conventillo (tipología porteña anterior y coetánea), para transformarse en una mera circulación peatonal (Ramos, 1998). Pero, aunque estos espacios de pasillo tenían que ver más con una mera operación de circulación, jerarquización y buena apariencia del conjunto para su mejor locación y rentabilidad, con la intervención más consciente y proyectada de estos espacios intermedios también es cierto que en muchos casos representó mejoras en la calidad de los espacios comunes, resignificando su sentido respecto a lo común, hasta el momento casi de simple servidumbre (Cutruneo, 2015). En este sentido, acá se plantea esta tipología como una oportunidad a seguir explorando formal y simbólicamente a través de la caracterización del pasillo y sus espacios comunes, con 
el fin de potenciar su carácter comunal a través de modificaciones y resignificaciones para su uso como herramienta proyectual.

\subsection{Pasajes}

Derivado del tipo anteriormente descrito, con el pasillo como eje estructurador de las unidades habitacionales y espacio común para los habitantes del conjunto, pero de circulación más amplia (entre tres y seis metros) y ahora transformado en calle peatonal con diseño de fachadas para la misma, se conformó la tipología del "pasaje".

Según Ramos (1998), este tipo de habitación colectiva, surgido a principios del siglo XX como parte de operaciones urbanísticas por englobamiento de lotes y particiones no convencionales de la manzana, acompañó el proceso de densificación urbana en horizontal y fue destinado a los sectores medios bajos (ver fig. 6).

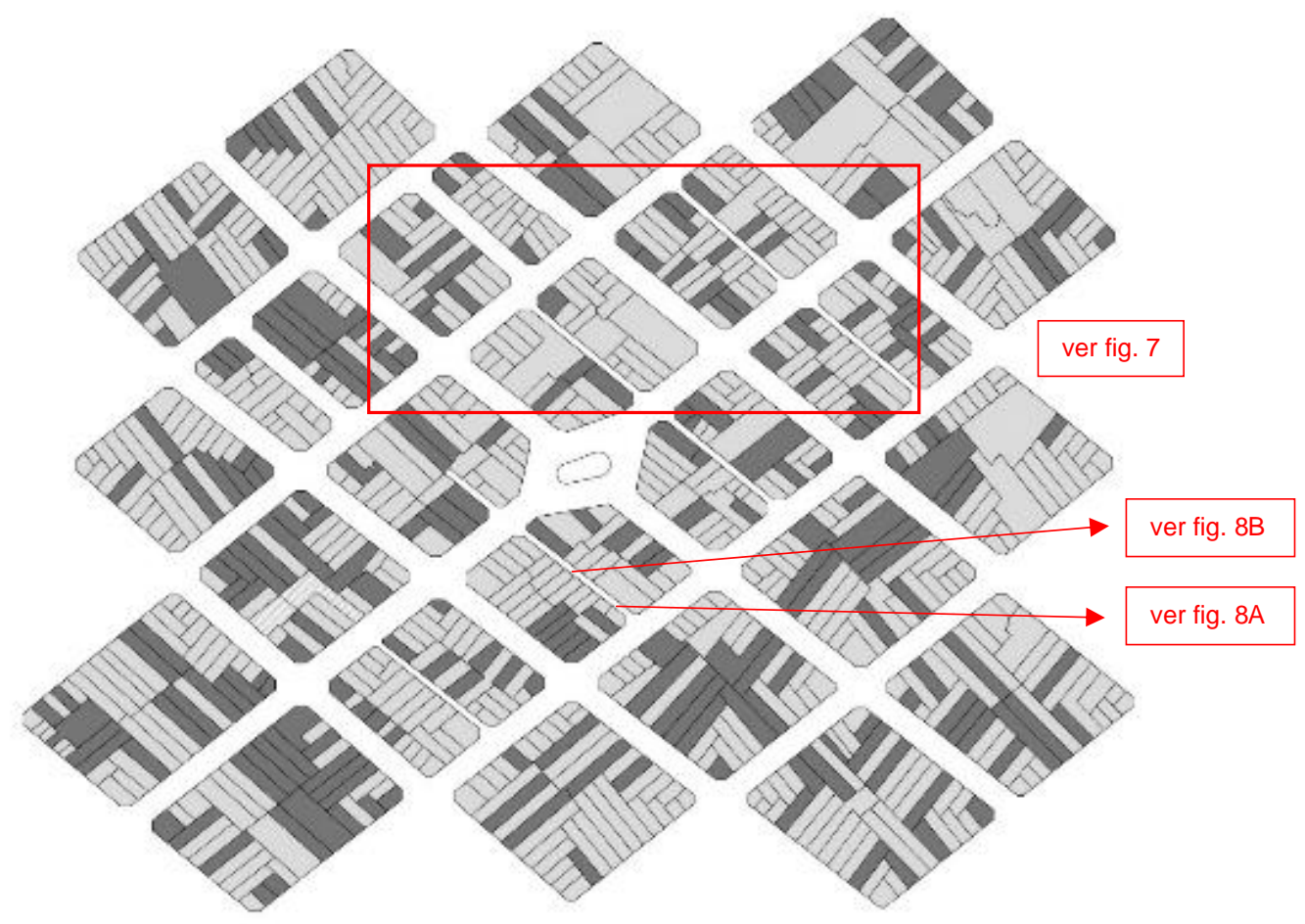

Fig. 6: Mapa del tipo de viviendas en Palermo Soho (antigua Villa Alvear). Los lotes pintados de gris oscuro representan la vivienda colectiva; los de color gris claro, la vivienda individual. Se evidencian los departamentos de pasillo y los pasajes identitarios del barrio. Elaboración propia a partir de la base de datos del mapa interactivo del GCBA.

Fueron conjuntos llevados a cabo por compañías inmobiliarias, cooperativas o sociedades de beneficencia, cuyos ejes estructuradores, ahora pasajes como calles peatonales, se disponían según formas diversas: en "l", en "L", en "U" o en "O", tipo "cul-de-sac" o con entrada y salida, de acceso libre o cerrados. Se dispusieron en uno o más niveles e incluso en algunos casos existía circulación vehicular interna.

En el barrio de Palermo, más allá de la proliferación, como decíamos, de los departamentos de pasillo, también se conformaron varios pasajes, alterando el ritmo de la grilla regular y, al mismo tiempo, ofreciendo una calidad espacial y una relación con la buscada escala humana, "atributos sumamente valorados en la actualidad y han sido objeto de una normativa especial en el Código de Planeamiento Urbano (CPU)" (Vecslir; Kozak, 2013: 152). En este sentido, el trazado de la Villa Alvear (área que hoy se conoce más por Palermo Soho y que tiene su epicentro en la Plaza Cortázar, más conocida como Plaza Serrano) es paradigmático por la conformación de medias manzanas rectangulares (ver fig. 7). Esta operación pudo ofrecer un mayor número de lotes de menor superficie, con la finalidad de poder ser más accesibles para las clases modestas que ahí se situaron. 


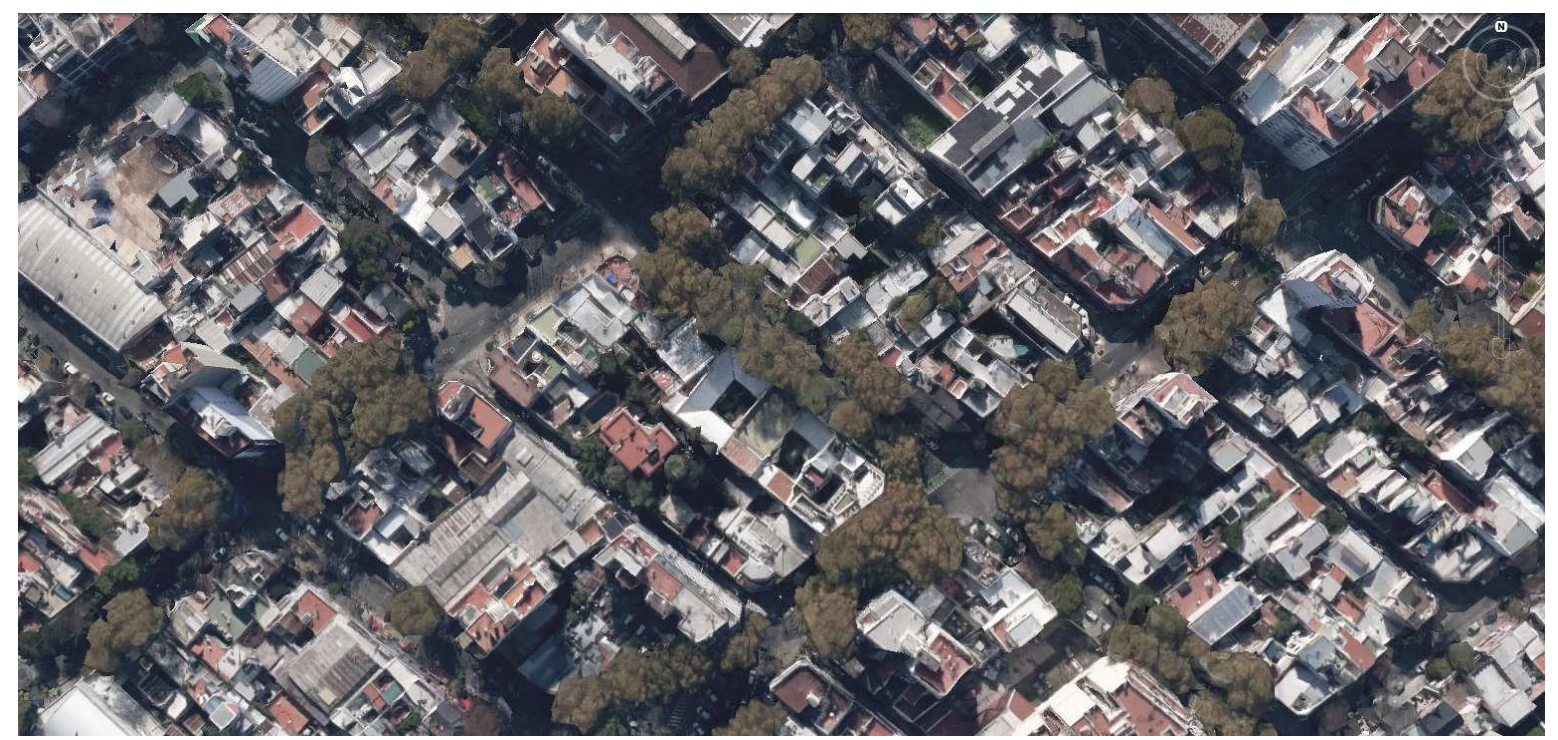

Fig. 7: Zoom del tejido de Palermo Soho. Se indica el recorte en la fig. 6. Fuente: GoogleMaps.

El carácter popular de esta zona contrasta con el cambio de perfil socio-económico de los cada vez más nuevos colonos, llegados en busca de dichas cualidades espaciales, sociales y culturales, destacando el valor agregado que pueden ofrecer este tipo de construcciones colectivas. Además, estos espacios comunes restringen el uso del automóvil, potenciándolos como espacios públicos de calidad, como extensiones de los espacios privados de los vecinos frentistas, pero también como ámbitos urbanos para el disfrute colectivo.

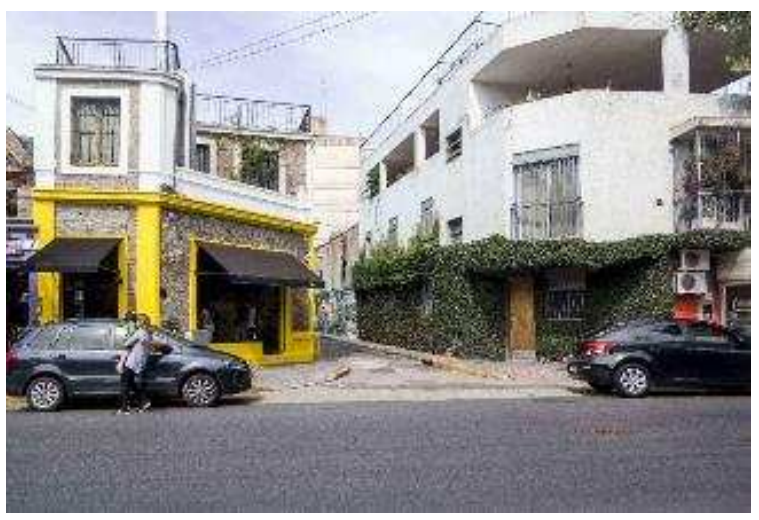

A

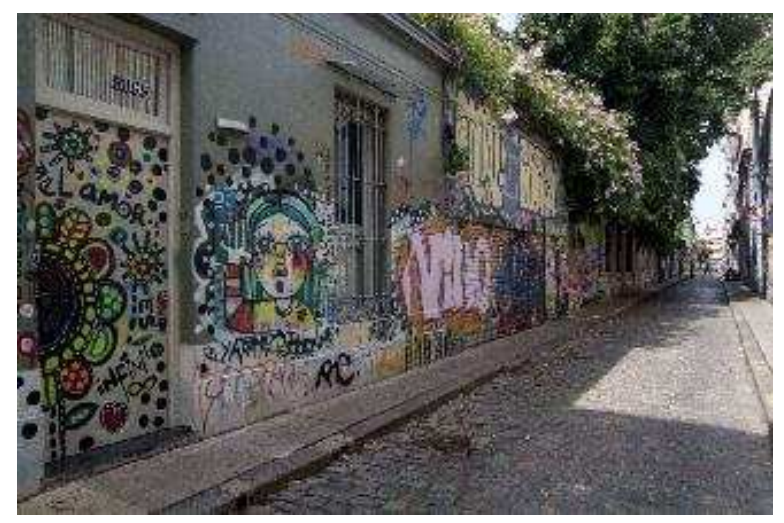

B

Fig. 8: Fotos A y B. Imágenes de pasajes en el barrio de Palermo Soho. Se marcan los puntos de vista en la fig. 6. Fotografías: Silvia Millanes. 


\section{BIBLIOGRAFÍA}

ALLEN, S. (2009), "Del objeto al campo: condiciones de campo en la Arquitectura y el Urbanismo" en Iñaki Ábalos (ed.), Naturaleza y artificio: el ideal pintoresco en la Arquitectura y el Paisajismo contemporáneos (Barcelona: Editorial Gustavo Gili).

AMIN, S. (2009), “¿Salir de la crisis del capitalismo o salir del capitalismo en crisis?”, El Viejo Topo, no 263. Disponible en: www.elviejotopo.com (consultado el 06.04.12).

ASENSIO, A. (2007), Arquitectura popular, la verdadera arquitectura sustentable, en: http://www.plataformaarquitectura.cl/2012/03/07/arquitectura-popular-la-verdadera-arquitectura-sustentable/ (consultado el 14.03.12).

BERGER, A. (2006), "Drosscape" en Waldheim (ed.), The Landscape Urbanism reader (New York: Princeton Architectural Press).

CONNOLLY, P. (2012), La ciudad y el hábitat popular: paradigma latinoamericano, en: http://www.ungs.edu.ar/catedrasur/wp-content/uploads/2012/11/12_CONNOLLY_VF.pdf (consultado el 20.03.16).

CORNER, J. (2009), "Terra fluxus" en Iñaki Ábalos (ed.), Naturaleza y artificio: el ideal pintoresco en la Arquitectura y el Paisajismo contemporáneos (Barcelona: Editorial Gustavo Gili).

- (2014), "Ecology and Landscape as agents of creativity" en Corner y Alison Bick Hirsch (eds.), The landscape imagination: collected essays of James Corner 1990-2010 (New York: Princeton Architectural press).

CUTRUNEO, J. P. (2015), Arquitectos y mercado inmobiliario. Vivienda e innovación tipológica Rosario, 1920-1948 (Rosario: UNR Editora).

DAVIS, M. 2006. Planet of slums (Londres: Verso) [ed. cast. 2007. Planeta de ciudades miseria (Madrid: Foca)]. Disponible en: http://redpaemigra.weebly.com/uploads/4/9/3/9/49391489/planeta_de_ciudades_miseria_-_davis_mike.pdf (consultado el 10.12.16).

DIEZ, F. (2011), "Normas y formas: regulación y tipología en Buenos Aires", Habitar Buenos Aires: las manzanas, los lotes y las casas (Buenos Aires: Bisman Ediciones).

FERNÁNDEZ CASTRO, J. (2007), "Metro-Intra-Meta. Categorías para leer y proyectar la Ciudad latinoamericana", en VI Jornadas de Investigación en Arquitectura, Farq UdelarR, Montevideo, en: http://fernandezcastro.com.ar/blog/wp-content/uploads/Metro-Intra-Meta.pdf (consultado el 04.02.16).

FERNÁNDEZ-SAVATER, A. (2013), "(María Naredo) Dos modelos de seguridad: policial y relacional”, en El Diario Digital, en: http://www.eldiario.es/interferencias/Maria-Naredo-seguridad-policialrelacional_6_198490169.html (consultado el 12.02.17).

GEHL, J. (2014), Ciudades para la gente, Buenos Aires, Editorial Infinito, en: http://www.urbangateway.org/system/files/documents/publicspace/cities_for_people-_spanish_final_ss2.pdf (consultado el 12.01.17).

GUTIÉRREZ, B. (2016a), La ciudad de código abierto como horizonte democrático transnacional, Democracia Abierta. Disponible en: https://www.opendemocracy.net/democraciaabierta/bernardo-guti-rrezgonz-les/el-c-digo-abierto-como-modelo-de-ciudad-1 (consultado el 15.09.16).

- (2016b), "Habitar las ciudades democráticas", en Diagonal Periódico. Disponible en: https://www.diagonalperiodico.net/saberes/31116-habitar-ciudades-democraticas.html (consultado el 16.08.14).

GUTIÉRREZ VALDIVIA, B. (2016), "La ciudad cuidadora", en Seres Urbanos, El País Digital, en: http://elpais.com/elpais/2016/03/18/seres_urbanos/1458284400_145828.html (consultado el 05.11.16).

HARVEY, D. (1973), Social Justice and the City (Londres: Edward Arnold) [ed. cast. 1977. Urbanismo y desigualdad social (Madrid: Siglo XXI)]. Disponible https://colectivociajpp.files.wordpress.com/2012/08/harvey-david-urbanismo-y-desigualdad-social.pdf (consultado el 16.12.16). 
- (2012), Rebel Cities: From the Right to the City to the Urban Revolution (London: Verso) [ed. cast. 2013. Ciudades Rebeldes. Del derecho de la ciudad a la revolución urbana (Madrid: Akal)]. Disponible en: http://www.cronicon.net/paginas/Documentos/CIUDADES_REBELDES.pdf (consultado el 12.12.16).

KAHATT, S. S. (2013), "Sociedad y paisajes emergentes. Apuntes a propósito de los concursos de desarrollo urbano e inclusión social de la CAF", en Revista Ciudad, n 4 , Lima, Colegio de Arquitectos del Perú, en: https://issuu.com/cappiura/docs/revista_ciudad_edici_n_n_4__ca (consultado el 09.02.17).

LAVAL, C.; DARDOT, P. (2014), Commun (Paris: Éditions La Découverte) [ed. cast. 2015. Común. Ensayo sobre la revolución en el siglo XXI (Barcelona: Gedisa)].

MASSEY, D. (2012), "Espacio, lugar y política en la coyuntura actual", en Revista Urban NSO4, Madrid, DUyOT-ETSAM-UPM, en: http://polired.upm.es/index.php/urban/article/view/1864/2117 (consultado el 02.05.16).

NAREDO, J. M. (1996), "Sobre el origen, el uso y el contenido del término sostenible", en Boletín CF+S 15 (Madrid: Instituto Juan de Herrera).

- (2001), "Ciudades y crisis de civilización", en Boletín CF+S 15 (Madrid: Instituto Juan de Herrera). Disponible en: http://habitat.aq.upm.es/boletin/n15/ajnar.html (consultado el 20.03.12).

PULEO, A. H. (2010), "Ecofeminismo: la perspectiva de género en la conciencia ecologista", en Claves del Ecologismo social (Madrid: Editorial Libros en Acción-Ecologistas en Acción).

RAMOS, J. (1998), La habitación popular urbana en Buenos Aires 1880-1945: una mirada tipológica (Buenos Aires: Instituto de Arte Americano).

RIFKIN, J. (2014), La sociedad de coste marginal cero. El internet de las cosas, el procomún colaborativo y el eclipse del capitalismo (Barcelona: Editorial Paidós).

SÁEZ, E.; GARCÍA, J.; ROCH, F. (2010), "La ciudad desde la casa: ciudades espontáneas en Lima", en Revista INVI, Santiago de Chile.

SASSEN, S. (1991), The Global City: New York, London, Tokyo (Princeton: Princeton University Press) [ed. cast. 1999. La Ciudad Global. Nueva York, Londres, Tokio (Buenos Aires: Eudeba)].

- (2016), The Global Street: Making the Political (New York: Columbia University).

SOLÀ-MORALES, I. (2009), "Terrain vague" en Iñaki Ábalos (ed.), Naturaleza y artificio: el ideal pintoresco en la Arquitectura y el Paisajismo contemporáneos (Barcelona: Editorial Gustavo Gili).

SUBIRATS, J.; MONTANER, J. M. (2012), Repensar las políticas urbanas (Barcelona: Diputació de Barcelona).

TAMAYO, L. (2016), "Claves para diseñar redes y comunidades colaborativas", en Ouishare Magazine, en: http://magazine.ouishare.net/es/2016/05/claves-para-disenar-un-sistema-colaborativo-

1/?utm_source=twitterfeed\&utm_medium=twitter (consultado el 06.08.16).

VECSLIR, L.; KOZAK, D. (2013), "Transformaciones urbanas en la manzana tradicional. Desarrollos fragmentarios y micro transformaciones en el tejido del barrio de Palermo, Buenos Aires", en Cuaderno Urbano. Espacio, cultura, sociedad (Resistencia: Universidad Nacional del Nordeste). 